\title{
The UbiBus Project: Using Context and Ubiquitous Computing to build Advanced Public Transportation Systems to Support Bus Passengers
}

\author{
Vaninha Vieira ${ }^{1}$, Ana Carolina Salgado ${ }^{2}$, Patricia Tedesco ${ }^{2}$, Valeria Times ${ }^{2}$, Carlos \\ Ferraz $^{3}$, Elisa Huzita ${ }^{4}$, Ana Paula Chaves ${ }^{5}$, Igor Steinmacher ${ }^{5}$ \\ ${ }^{1}$ Department of Computer Science - Federal University of Bahia - Salvador-BA, Brazil \\ ${ }^{2}$ Informatics Center - Federal University of Pernambuco - Recife-PE, Brazil \\ ${ }^{3}$ C.E.S.A.R. - Recife- PE, Brazil \\ ${ }^{4}$ Department of Informatics - State University of Maringá - Maringá-PR, Brazil \\ ${ }^{5}$ UTFPR - Campo Mourão-PR, Brazil \\ vaninha@dcc.ufba.br, \{acs, pcart, vct, cagf\}@cin.ufpe.br, \\ emhuzita@din.uem.br, \{anachaves,igorfs\}@utfpr.br
}

\begin{abstract}
Urban mobility is a problem that affects all cities. Providing real time information that can assist citizens on planning their trips by choosing times and itineraries more appropriate to their needs are essential on smart cities. Our project, named UbiBus, investigates how Computational Context and Ubiquitous Computing can be applied to Intelligent Transportation Systems to aid bus passengers mobility on cities, since dynamic real-time factors can affect transportation means. This paper describes the overall ideas concerning the UbiBus Project and presents some of the applications under development with their preliminary results.
\end{abstract}

\section{Introduction}

Big cities are increasingly suffering from the problem of urban mobility. Several problems, such as constant traffic jam, lack of investments in road infrastructure, and poor quality of public transportation services make citizens daily life stressful and complicated [Chaves et al. 2011]. Stimulating the use of public transportation is essential to support urban mobility, because it reduces the number of cars on public roads [Barry 2010][Caulfield and O'Mahony 2007].

Intelligent Transportation Systems (ITS) aim "to combine high technology and improvements in information systems, communication, sensors, and advanced mathematical methods with the conventional world of surface transportation infrastructure" [Sussman 2005]. APTS (Advanced Public Transportation Systems) is a subarea of ITS interested on providing passengers information and technologies to enhance public transportation system operations [Sussman 2005]. APTS often involves situations and objects related to issues such as navigation, mobility and traffic, i.e., aspects that have greatly vary their behavior. Thus, APTS users need transportation information to be available "anytime, anywhere, from any device" [Weiser 1991]. Understanding the context of transportation vehicles (e.g. current location, speed, availability), routes (e.g. traffic jam, accidents, obstructions), passengers (e.g. physical 
disability, preferences, tourism) or environmental conditions (e.g. rush hour, rainy days, natural disasters) are essential for APTS systems to better assist passengers.

In our work we investigate how the Ubiquitous Computing [Weiser 1991] and Computational Context [Schilit et al 1994] areas can support APTS development. In this light, we propose a ubiquitous, context-sensitive advanced public transportation solution, called UbiBus [Vieira et al 2011]. UbiBus objectives include to specify and to implement technological solutions (e.g. models, algorithms, tools and applications) to support real time information delivery about public transportation, in particular urban buses (e.g. route recommendation, bus location and arrival time estimative, traffic occurrences). Applications being developed use real time context information collected from different sources, considering vehicles and passengers mobility, and dynamic factors that can affect the transportation (e.g. occurrences on the routes). To support the ubiquity principles, applications can be accessed seamlessly from different devices (e.g. desktops, terminals on bus stops, displays inside a bus or mobile phones).

This paper presents the overall ideas and preliminary results on UbiBus. It discusses related work in Section 2. Section 3 describes its overall architecture. Some preliminary results achieved with implemented applications are presented in Section 4. Finally, Section 5 presents our final considerations and ongoing work.

\section{Related Work}

Several applications have been developed to assist users in finding out information about public transportation means in a city. Waze ${ }^{1}$ generates maps according to the route informed by the user, and presents traffic data collected in real time from other people who are also using the software [Ogliari 2011]. OneBusAway [Ferris et al 2010] is directed to bus users in Seattle and its vicinity, and presents all bus stops closer to the user's location, the lines associated to each stop and their current schedules, updated in real time by the bus company; it also provides a web interface that displays a map with the bus stops' locations and the timetables for all vehicles associated to those stops. ToTransit $^{2}$ displays the street-cars location in Toronto, Canada, with information provided, in real time, by the transportation companies; Bus Maps London ${ }^{3}$ shows static information about bus stops, routes and schedules for the city of London-UK. Google Maps $^{4}$ also presents APTS features for some cities, allowing people to plan their routes using public transportations. Moreover, Google Maps API is used to compose most of the applications mentioned on this section.

Despite those initiatives, it is difficult to obtain dynamic information about public transportation conditions, since many unexpected events may occur in the route (e.g. traffic jams, accidents). Most solutions strongly depend on information provided by official transportation companies and use proprietary methods and algorithms. Our proposal aims to build open source systems with free available models, algorithms and tools that can be used and evolved by the community, on different cities.

\footnotetext{
${ }^{1} \mathrm{http}: / /$ www.waze.com/

${ }^{2} \mathrm{http}: / /$ totransit.ca/

${ }^{3}$ http://www.tfl.gov.uk/tfl/gettingaround/maps/buses/

${ }^{4} \mathrm{http}: / /$ maps.google.com
} 


\section{The UbiBus Project}

UbiBus investigates different aspects related to: (i) context acquisition, processing and management for either static or dynamic information; (ii) algorithms and models to estimate arrival times and recommend routes and vehicles; (iii) geo information visualization and interpretation, considering large volume of data from transportation and routes; (iv) middleware support for building context-sensitive ubiquitous systems; and (v) development of adaptable, multi-platform applications to assist passengers. Figure 1 presents an overview of the UbiBus Architecture with its 5 main layers: Data, Communication, Acquisition, Processing and Application.

The Data Level manages data processed by the system, including georeferenced spatial context for the trajectories of moving objects (e.g. vehicles and people). Different dynamic context information about buses, bus stops and passengers may be considered. Data on the positioning of mobile objects are continually updated, to represent their movements over time.

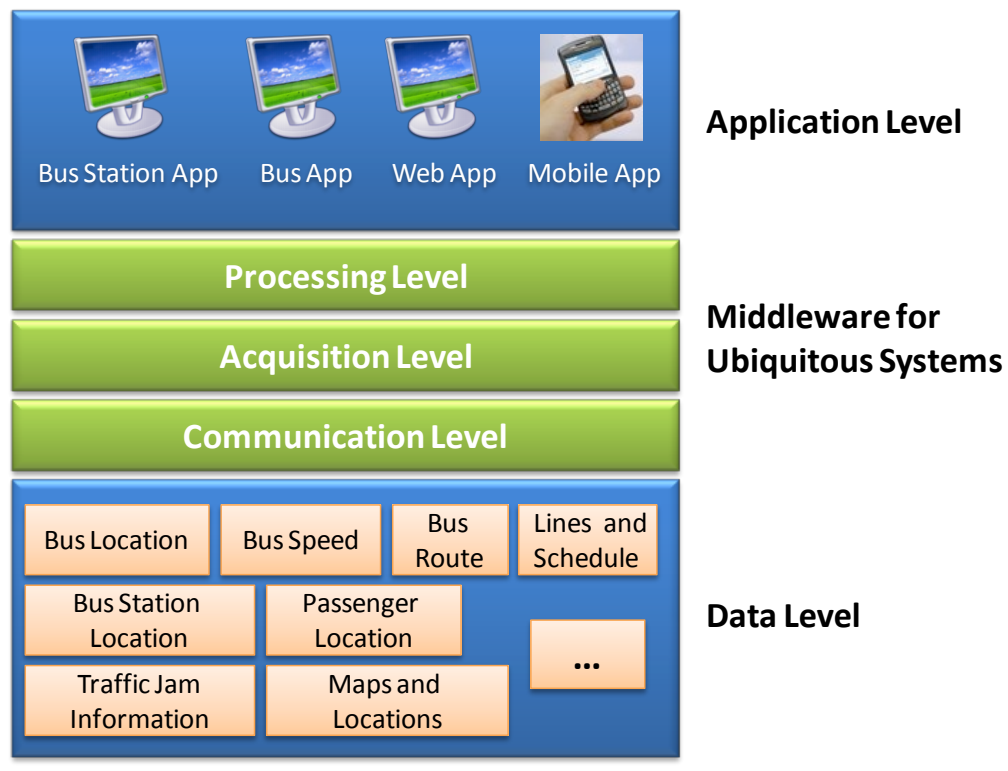

Figure 1. The UbiBus Architecture Overview [Vieira et al 2011]

The Communication Level allows the connection between static and dynamic elements that compose the transportation infrastructure, allowing information exchange in real time. Advances and standardization of wireless communication technologies allows short and long-range communications. Information may be offered directly to users, considering the wide availability of connectivity based on wireless communication technologies between mobile devices and laptops. The Acquisition Level is responsible for gathering static and dynamic data from different sources, sending them to the Data Level. For instance, GPS systems installed on buses can provide bus location and speed information; traffic level can be inferred by text mining social networks; external meteorology systems may provide weather information; and passengers' location can be achieved by a mobile. The Processing Level uses acquired contextual information along with mathematical and algorithmic solutions to calculate other information, such as the estimated bus arrival time. It is also responsible for preprocessing acquired information ensuring compatibility between different context sources and the incorporation of semantics to mobile elements trajectories. 
The Application Level contains the different types of applications developed on top of the UbiBus infrastructure. These applications should be adjusted to different platforms and devices (e.g. Web, desktop, mobile devices, terminals at bus stops or displays inside a bus). Web applications should provide: i) arrival times for each bus at each stop; ii) definition of best routes based on priorities (cost, time, comfort); iii) traffic level in each area, route or region; iv) services to support the passenger on choosing the vehicle according to preferences or needs; and others. Mobile applications are similar to web applications, but with interface adaptations for mobile devices and also the possibility of using device's geographical position for more contextualized information. Bus applications are available on terminals inside the buses and provide information about the current trip, so passengers can visualize information about the trip and change their original plans due to unforeseen events. Bus Station applications provides information to passengers that are waiting for a bus in a bus stop regarding buses they can take, estimated arrival time and their current location.

To support developing different types of applications, UbiBus proposes a multiparadigm, extensible and message oriented middleware for Ubiquitous Systems. It encompasses the activities presented on the Communication, Acquisition and Processing levels. A middleware plays an important role in developing context sensitive and ubiquitous applications since it facilitates the communication and coordination of distributed software components dealing, in a transparent way, with the difficulties and complexities introduced by mobility and wireless communication [Souto et al 2004].

\section{Preliminary Results}

This section presents an overview of the preliminary results achieved with the UbiBus project, concerning some developed applications, as described in the following.

\subsection{Your City on Time (YCIT)}

YCIT is a bus station application type proposed in [Caldas 2010]. It uses contextual information to estimate a bus arrival time at a given bus stop. A map is used to contextualize the bus location, whereas a table shows: the bus lines that serve that bus stop; the current distance and estimated arrival time for each bus. To calculate the estimated arrival time, YCIT considers contextual elements such as: bus location, current speed and average speed; bus stop location; route stretch average speed and traffic level. To infer traffic level in a stretch we used two incremental weighted update formulas, proposed in [Sananmongkhonchai et al 2008]. The contextual elements bus speed, bus location and bus average speed are acquired from GPS. The front-end application uses the Google Maps API to provide directions and distances between a bus and a bus stop in its itinerary. Currently, the application works on web browsers, but we intend to migrate it to mobile phones to support passengers mobility.

\subsection{UbibusRoute}

UbibusRoute [Lima et al 2012] uses information coming from social networking sites (in this first prototype we have used Twitter) to recommend routes to users, thus supporting them in their decision making processes. Based on the context of the user and of the route and buses, the application computes the possible routes (for each user to get to their destination), indicating on a map the route to follow. UbibusRoute was designed as a client-server application, where the client is a mobile application (that can 
work with any available operating system) that communicates with the server. The application has two Databases: one stores contextual traffic data, and the other static data (e.g. bus stops, bus lines and routes). The Server module is divided into three main components: the Route Identifier, responsible for identifying all possible routes according to the user's location or the selected bus stop; the Route Indicator, responsible for selecting the best route according to the user's preference (time, cost or distance); the Contextual Information Extractor, that acquires information from social networks and checks the current state of traffic. Additionally, there is a module (that wraps up the social networks) that works in capturing information related to traffic.

\subsection{EPITrans}

The Extraction, Processing and Inference of Transport information (EPITrans) is an application that offers updated and useful information to the users extracted from Facebook messages on a map. It exploits the cooperation between the Facebook social network users, by mining and extracting information related to the transit on the cities from the messages posted by users. A navigable map points the most current traffic events, informed by the users.

\subsection{Occurrences reporting and visualization}

We have proposed applications based on social network and crowdsourcing to support information visualization about facts that occur and affect public transportation. They access citizens' knowledge about real-time conditions available on social networks or other tools on the Internet. They are: (i) Collaborative routes editing is a tool integrated to Facebook which enables users to collaboratively create routes that can be visualized and edited by the user's contacts [Alves et al 2011]. In the future, the users will be able to indicate preferred routes, comment or give a reputation for a route, and others; (ii) Occurrence report using mobile devices takes advantage of the mobility trend to enable passengers to provide and get real time information about the public transportation they are using; users can report facts that occur in their route (these facts will be posted as Twitter messages) and retrieve facts that affect a given bus line; messages can be visualized textually or in a map showing most recent occurrences; (iii) Occurrence reporting and visualization via web aims to enable users to report occurrences using a collaborative map; recorded occurrences are displayed as a pointer in the map, facilitating the occurrence location identification; and (iv) Traffic conditions visualization, a web application based on maps that aims to display the possibility of traffic problems in a given location; it uses different colors in each section of a route, based on amount, intensity and type of messages reported.

\section{Conclusions and Further Work}

This paper presented an overview of the UbiBus Project, a multi-institutional initiative in the scope of smart cities, involving five institutions, being four universities and one information company, that aims to integrate methods and techniques from several areas (e.g. Ubiquitous Computing, Computational Context, Middleware and Geographical Information Systems) to build solutions for the advanced public transportation systems. The paper also presented some preliminary applications developed on the context of UbiBus. The project is still in progress and there is much work to be done to achieve its goals. Currently, we are working on refining the specification and development of the 
five levels indicated in the UbiBus architecture (Figure 1), the Middleware for Ubiquitous Systems and on the applications described in Section 4, improving them and identifying additional requirements. To evaluate the project ideas, we are in contact with some cities transportation administrations to establish partnerships.

\section{Acknowledgments}

This work is supported by the CNPq (process 560135/2010-6) and [partially] supported by the INES ${ }^{5}$. Authors thank UbiBus researchers from UFPE, UFBA, UTFPR, UEM and CESAR. Special thanks to Luiz Caldas, Vanessa Gomes, Adriano Oliveira, Tainan Gomes and all students involved on the development of the UbiBus applications.

\section{References}

Alves, L. P. S., Chaves, A. P., Steinmacher, I. F. Um aplicativo baseado em inteligência coletiva para compartilhamento de rotas em redes sociais. VIII Simpósio Brasileiro de Sistemas Colaborativos, Paraty-RJ, 2011

Barry, K. How smartphones can improve public transit. Wired Magazine, 2010.

Caldas, L. R. Desenvolvimento de Uma Solução Sensível ao Contexto Como Suporte a um Sistema de Transporte Público. Monografia de Conclusão de Curso - Ciência da Computação. 2010.

Caulfield, B., O'Mahony, M. An examination of the public transport information requirements of users. IEEE Transactions on Intelligent Transportation Systems, 8:1, 2007, 21-30.

Chaves, A. P., Steinmacher, I., Vieira, V. Social networks and collective intelligence applied to public transportation systems: A survey. In: VIII Simpósio Brasileiro de Sistemas Colaborativos, Paraty-RJ, 2011.

Ferris, B., Watkins, K., Borning, A. Location-aware tools for improving public transit usability. IEEE Pervasive Computing, 9, 2010, 13-19 [http://www.onebusaway.org/]

Lima, V., Magalhães, F., Tito, A., Santos, R., Ristar, A., Santos, L., Vieira, V., Salgado, A.C. UbibusRoute: Um Sistema de Identificação e Sugestão de Rotas de Ônibus Baseado em Informações de Redes Sociais. VIII SBSI - Trilha de Ferramentas. São Paulo-SP, 2012.

Ogliari. R. Crowdsourcing, muito melhor com mobile. Revista Espírito Livre, 26, 2011, 51-55.

Sananmongkhonchai, S., Tangamchit, P., Pongpaibool, P. Road traffic estimation from multiple GPS data using incremental weighted update. In Proc. of 8th Int. Conf. on ITS Telecommunications, Phuket, Thailand, 2008, 62-66.

Schilit, B., Adams, N., Want, R. Context-Aware Computing Applications. In Workshop on Mobile Computing Systems and Applications. Santa Cruz, CA, 1994, 90-98.

Souto, E., Guimarães, G., Vasconcelos, G., Vieira, M., Rosa, N., Ferraz, C. A message-oriented middleware for sensor networks, 2nd Workshop on Middleware For Pervasive and Ad-Hoc Computing, Ontario, Canada, 2004, 127-134.

Sussman, J. Perspectives on Intelligent Transportation Systems. Springer, New York, USA, 2005.

Vieira, V., Caldas, L. R., Salgado, A. C. Towards an Ubiquitous and Context Sensitive Public Transportation System. In: 4th International Conference on Ubimedia Computing, São Paulo, 2011, 174-179.

Weiser, M., "The computer for the 21st century", Scientific American, 265:3. pp.66-75, 1991.

\footnotetext{
${ }^{5}$ http://www.ines.org.br
} 